\title{
Ultrathin electrochemically driven conducting polymer actuators: fabrication and electrochemomechanical characterization
}

\author{
Tan Ngoc Nguyen ${ }^{\mathrm{a}, \mathrm{c}}$, Kätlin Rohtlaid ${ }^{\mathrm{b}}$, Cédric Plesse ${ }^{\mathrm{b}}$, Giao T.M. Nguyen ${ }^{\mathrm{b}}$,

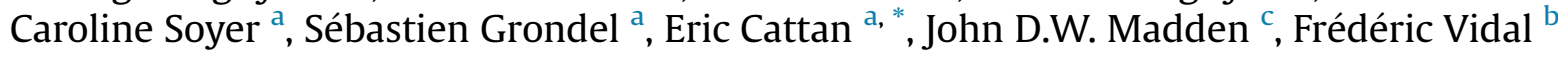 \\ ${ }^{a}$ Univ. Valenciennes, CNRS, Univ. Lille, Yncrea, Centrale Lille, UMR 8520 IEMN, DOAE, F-59313, Valenciennes, France \\ ${ }^{\mathrm{b}}$ LPPI, EA2528, Institut des Matériaux, Université de Cergy-Pontoise, 5 Mail Gay Lussac, Neuville sur Oise, F-95031, Cergy Cedex, France \\ ${ }^{\mathrm{c}}$ Advanced Materials and Process Engineering Laboratory, University of British Columbia, Vancouver, BC, Canada
}

\section{A R T I C L E I N F O}

\section{Article history:}

Received 1 October 2017

Received in revised form

31 January 2018

Accepted 1 February 2018

\section{Keywords:}

PEDOT-Based actuators

Layer by layer method

Vapor phase polymerization

Volumetric capacitance

Electronic conductivity

Ionic conductivity

Force generation

Bending actuation

\begin{abstract}
A B S T R A C T
Electronic conducting polymer based-actuators have attracted lots of interest as alternative materials to traditional piezoelectric and electrostatic actuators. Their specific characteristics such as their low operating voltages and large strains should allow them to adapt better to soft microstructures. Recently, poly (3,4-ethylenedioxythiophene) (PEDOT) - based ionic actuators have overcome some initial stumbling blocks to widespread applications in the microfabricated devices field. These trilayer bending microactuators were fabricated (i) by sequential stacking, using a layer by layer polymerization (LbL) of conducting polymer electrodes and a solid polymer electrolyte and (ii) by micro-patterning, using standard microsystems processes. While microfabrication processing of a trilayer actuator, involving no manual handling has been demonstrated, their bending performances remain limited for practical applications. Moreover, the complete characterization of their electrical, electrochemical, and mechanical properties has never been investigated. This paper describes the optimization of PEDOT electroactive electrodes synthesized with a vapor phase polymerization process. Influence of synthesis parameters on thickness, electronic conductivity and volumetric charge density were studied to determine the guidelines for synthesizing highly efficient electrodes. Afterwards, these parameters are used to guide the LbL synthesis process of ultrathin trilayer actuators. Electrochemical and mechanical properties of the resulting microactuators have been thoroughly characterized. Bending deformation and output force generation have been measured and reached $0.5 \%$ and $11 \mu \mathrm{N}$ respectively. This constitutes the first characterization of ionic PEDOT-based microactuators operating in air of such a thin thickness ( $11 \mu \mathrm{m}$ dry and $18.3 \mu \mathrm{m}$ swelled in 1-Ethyl-3-methylimidazolium bis(fluorosulfonyl)imide (EMImTFSI)). These actuators and their actuation properties are promising for future soft microsystem devices where the use of polymer actuators should be essential.
\end{abstract}

(c) 2018 Elsevier Ltd. All rights reserved.

\section{Introduction}

Ionic electroactive polymer (IEAP) actuators have attracted a lot of interest of researchers from different domains since they can be used in a variety of applications: locomotion systems [1], Braille displays [2], steerable micro catheters [3], micro pumps [4,5], microactuators [6-8]. IEAP actuators have many attractive features including low operating voltages and large strains when compared to conventional materials [9]. Among different types of IEAPs, poly(3,4-ethylenedioxythiopene) (PEDOT) based-actuators have

\footnotetext{
* Corresponding author.

E-mail address: eric.cattan@univ-valenciennes.fr (E. Cattan).
}

received significant attention because of their highly reversible, fast switching redox processes [10]. Also, they are lightweight, biocompatible, produce high stress ( 10 MPa) [9], high power/ weight ratio [11], significant strain (up to 1\%), require low operating voltages (typically $<3$ Vpeak-peak (Vpp)) [12] in solutions or in open-air condition [13], can be electronically controlled with reasonable frequency response $(>50 \mathrm{~Hz})$ and are potentially suitable for microscale applications [13,14]. The actuation is obtained when the electronic conducting polymer (ECP) is oxidized or reduced electrochemically [15-19]: ions and solvent molecules, coming from a surrounding electrolyte, are inserted or expelled from the ECP in order to insure the overall electroneutrality which results in a variation of the ECP volume, or in short, this ECP 
actuator responses to the consumed charge. For a particular case, where the ionic liquid (EMImTFSI) is used, the electrochemical reactions driving the actuator displacement under an electrical stimulation is:

$$
\begin{aligned}
& {\left[\left(\text { PEDOT }^{0}\right), \mathrm{n}\left(\text { TFSI }^{-}\right), \mathrm{n}\left(\text { EMlm }^{+}\right)\right] \underset{\text { Reutuction }}{\stackrel{\text { Oxidation }}{\rightleftarrows}}} \\
& \quad \times\left[\left(\text { PEDOT }^{\mathrm{n}+}\right), \mathrm{n}\left(\text { TFSI }^{-}\right)\right]+\mathrm{n}\left(\text { EMlm }^{+}\right)+\mathrm{n}\left(\mathrm{e}^{-}\right),
\end{aligned}
$$

where $\mathrm{TFSI}^{-}$are immobilized anions which are trapped between PEDOT backbone chains in oxidized state, and $\mathrm{EMIm}^{+}$are mobilized cations driving the actuation [20].

To operate in open-air, a trilayer configuration [21-23] is the most described: two ECP electrodes sandwiching a solid polymer electrolyte (SPE) layer that will act as an ion reservoir.

For microscale actuators, the thickness must be less than $20 \mu \mathrm{m}$ to be compatible with microsystem technologies (photolithography, etching process ...) which is the reason why the layer-bylayer (LbL) approach has been developed recently [24]. The bending microactuators were fabricated by sequentially stacking layers using a layer by layer polymerization of conducting polymer electrodes and a SPE. Each layer was deposited by spin-coating to accurately control the thicknesses. PEDOT can be fabricated in-situ via electropolymerization [25] or via vapor phase polymerization (VPP) [26]. In this work the first and last layers of the actuators were obtained using VPP of 3,4-ethylenedioxythiophene (EDOT). The intermediate SPE layer was synthesized as a semiinterpenetrating polymer network (semi-IPN) combining poly(ethylene oxide) (PEO) network for ionic conductivity and nitrile butadiene rubber (NBR) for mechanical strength [23,27].

For the LbL process, while the proof of concept has been demonstrated previously, then the resulting performances remained relatively poor $(0.13 \%$ strain and $0.75 \mu \mathrm{N}$ of generated force) [24] mainly due to the low electroactivity of PEDOT electrodes obtained by VPP. Practical use of such microactuators and integration into innovative microelectromechanical systems requires improved performances. Moreover, any real application requires precise control and prediction of the performances. While models have been developed [28-30], they require precise electrical, electrochemical and mechanical characterizations of actuators, which have never been performed on these materials.

In this paper, we will first describe the VPP synthesis for optimization of PEDOT electrodes to provide highly electroactive electrodes, suitable for efficient microactuators. Microbeams of the actuators will be then prepared using the LbL approach and the resulting devices will be thoroughly characterized. More specifically, electrochemical parameters such as the volumetric capacitance, the ionic conductivity of the SPE, and the electronic conductivity of the ECP, will be measured. The Young's modulus, the curvature and the blocking force will describe the mechanical and electromechanical properties. Large improvement in actuator's performances and the first complete characteristics have been obtained, setting the stage for a potential integration into a micromechanical structure.

\section{Trilayer synthesis}

\subsection{Materials}

Poly(ethylene glycol) methyl ether methacrylate (PEGM, $\mathrm{M}_{\mathrm{n}}=500 \mathrm{~g} \mathrm{~mol}^{-1}$ ), poly(ethylene glycol) dimethacrylate (PEGDM, $\left.\mathrm{M}_{\mathrm{n}}=750 \mathrm{~g} \mathrm{~mol}^{-1}\right)$, cyclohexanone $(>99.8 \%)$ and 3,4ethylenedioxythiophene (EDOT, distilled under reduced pressure) were obtained from Sigma Aldrich. Iron(III) p-toluene sulfonate Clevios $^{\mathrm{TM}}$ CB 55 V2 (55 wt\% in butanol, $\mathrm{Fe}(\mathrm{OTs})_{3}$ in $\mathrm{BuOH}$ ) was purchased from HERAEUS. 1-butanol (99\%), initiator dicyclohexyl peroxydicarbonate (DCPD), 1-ethyl-3-methylimidazolium bis(trifluoromethanesulfonyl)imide (EMImTFSI 99.9\%) and nitrilebutadiene rubber, were used as supplied from Alfa Aesar, Groupe Arnaud, Solvionic and LANXESS, respectively.

\subsection{PEDOT electrode fabrication}

The fabrication process of the PEDOT electrodes was performed as described in the work of Maziz [31] and is depicted in Fig. 1. The PEDOT electrode layers were obtained from EDOT VPP, first described by Winther-Jensen [26]. The VPP of EDOT was carried out with a direct chemical oxidation using the commercial solution of Iron(III) tosylate $\mathrm{Fe}(\mathrm{OTs})_{3}$ ( $55 \mathrm{wt} \%$ in butanol). PEO precursors (mPEG) composed of $50 \mathrm{wt} \%$ of PEGM and $50 \mathrm{wt} \%$ of PEGDM were added as a monomer and a crosslinker, respectively, to the $\mathrm{Fe}(\mathrm{OTs})_{3}$ solution. Additionally, DCPD ( $3 \mathrm{wt} \% \mathrm{vs} \mathrm{mPEG}$ ) as the radical initiator for mPEG polymerization was introduced to the solution. The latter was then stirred until dissolution and degassed. The oxidant solution was then spin-coated onto a substrate and exposed to EDOT vapor for a fixed time at a fixed temperature. EDOT VPP was carried out under primary vacuum by heating liquid EDOT monomers that evaporate and polymerize on the oxidant solution. The EDOT VPP was followed by the final heat treatment for MPEG polymerization/ crosslinking $\left(3 \mathrm{~h}\right.$ at $50^{\circ} \mathrm{C}$ ) to obtain PEDOT/PEO composite electrodes. PEDOT electrodes were swollen in ionic liquid (EMImTFSI) for further characterization.

The final properties (thickness, electronic conductivity and volumetric charge density (VCD)) of the PEDOT electrodes were studied as a function of: composition of oxidant solution (content of mPEG), rotation speed of spin-coater for deposition of oxidant solution, EDOT VPP time and temperature. The synthesis initial conditions for PEDOT electrode study were $55 \% \mathrm{Fe}(\mathrm{OTs})_{3}$ in $\mathrm{BuOH}, 10 \%$ mPEG in the oxidant solution, the spin coating speed, acceleration and duration were $2500 \mathrm{rpm}, 1000 \mathrm{rpm} \mathrm{s}^{-1}$, and $30 \mathrm{~s}$, respectively, the EDOT VPP time of $30 \mathrm{~min}$ and temperature of $40^{\circ} \mathrm{C}$ were used. When one parameter was changed, the others remained the same as in the initial parameters. The range of values for each parameter varied is presented in Table 1.

The volumetric charge density, $\rho$, was calculated using the expression:

$\rho=\frac{\int_{0}^{T / 2} i(t) d t}{l b h}(\mathrm{C} / \mathrm{m} 3)$,

where $i(t)$ is the measured current using setup in Fig. SI1a (refer to the supporting information), $\mathrm{T}$ is the duration of one cycle of applied voltage, and $l, b, h$ are the length, width, and thickness of the PEDOT electrode, respectively.

\subsection{Microactuator fabrication}

The trilayer actuator was synthesized using a LbL method. In this process, all the layers are spin-coated on top of the previous layers and the thickness can be controlled extremely accurately by adapting the speed of rotation. The oxidant solution was prepared by adding PEO precursors ( $50 \mathrm{wt} \%$ PEGM and $50 \mathrm{wt} \%$ PEGDM) into a commercial $\mathrm{Fe}(\mathrm{OTs})_{3}$ solution. The PEO precursors (mPEG) were added to each layer and polymerized at the end of the process throughout the trilayer structure to improve adhesion between the layers. The solution was then stirred for $10 \mathrm{~min}$ and spin-coated onto a two-inch silicon wafer. The EDOT VPP was carried out in 

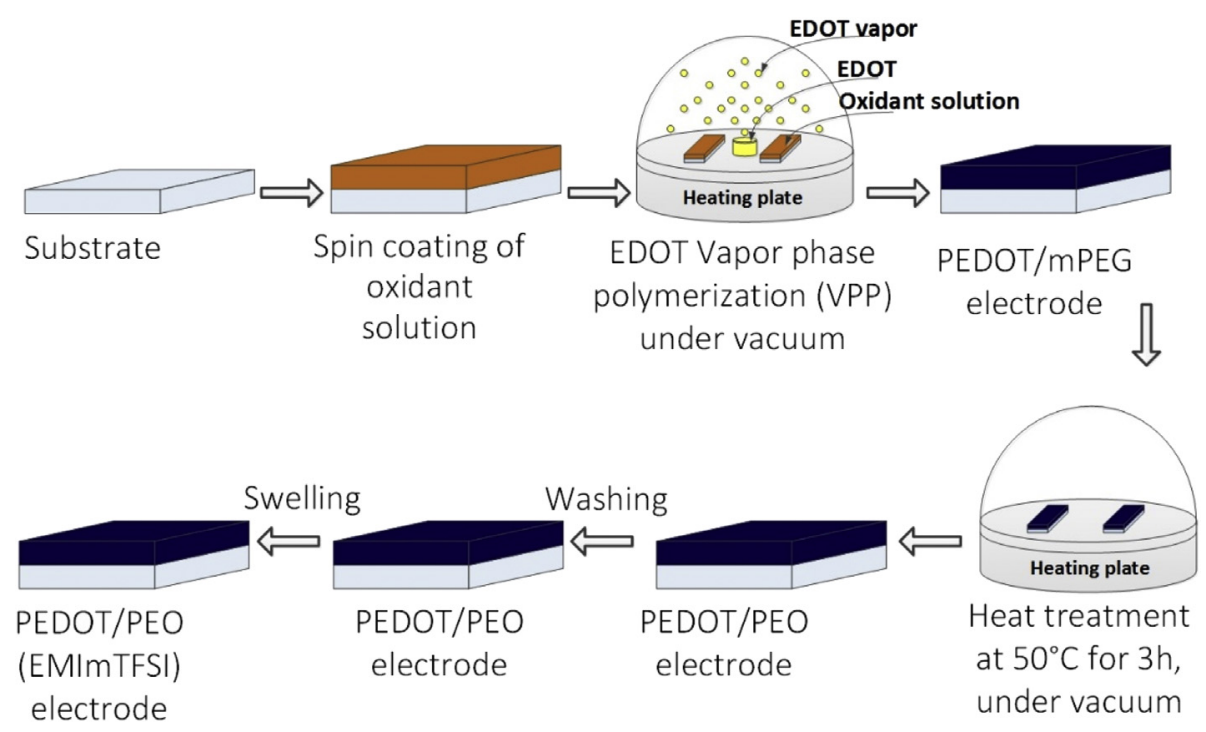

Fig. 1. Fabrication process of PEDOT electrodes.

Table 1

The range of values for each parameter varied for PEDOT electrode optimization. The acceleration $1000 \mathrm{rpm} \mathrm{s}^{-1}$ and duration $30 \mathrm{~s}$ for spin-coating remained always the same.

\begin{tabular}{lll}
\hline Parameter changed & Initial parameters & Range of values \\
\hline mPEG content & $10 \%$ & $0 \%-30 \%$ \\
Spin coating speed & $2500 \mathrm{rpm}$ & $1000 \mathrm{rpm}-2500 \mathrm{rpm}$ \\
EDOT VPP time & $30 \mathrm{~min}$ & $30 \mathrm{~min}-180 \mathrm{~min}$ \\
EDOT VPP temperature & $40^{\circ} \mathrm{C}$ & $30^{\circ} \mathrm{C}-80^{\circ} \mathrm{C}$ \\
\hline
\end{tabular}

the same manner as in the PEDOT electrode fabrication section during fixed time and at a fixed temperature.

During the next step, the SPE layer, based on a semi-IPN architecture according to a procedure described in Ref. [24], was prepared: The NBR solution (20 wt\% NBR and $80 \mathrm{wt} \%$ cyclohexanone) was mixed with PEO precursors (75 wt\% PEGM and 25 wt\% PEGDM vs. NBR). A free radical initiator DCPD ( $3 \mathrm{wt} \%$ vs PEO precursors) was then added to the solution, stirred for $15 \mathrm{~min}$ and degassed. A homogeneous mixture was obtained and spin-coated $(2000 \mathrm{rpm}$, $1000 \mathrm{rpm} \mathrm{s}^{-1}, 30 \mathrm{~s}$ ) on top of the first PEDOT electrode layer. The pre-polymerization was carried out under continuous supply of $\mathrm{N}_{2}$ at $50{ }^{\circ} \mathrm{C}$ during $45 \mathrm{~min}$ to enable the formation of the PEO network and to improve the adhesion between the first two layers.

The second PEDOT electrode layer was synthesized in the same way as the first one. The oxidant solution was prepared, spin coated on top of the PEDOT/SPE bilayer, and EDOT VPP was carried out under the vacuum in the same way as for the first electrode. During this step, DCPD ( 3 wt\% vs PEO network) was also added to the oxidant solution to initiate the polymerization of PEO network.

After EDOT VPP of the second electrode layer, the trilayer was placed under continuous supply of $\mathrm{N}_{2}$ for a final heat treatment step $\left(3 \mathrm{~h}\right.$ at $50^{\circ} \mathrm{C}$ ) [24] in order to polymerize the PEO precursors in every layer. This step provides a final intralayer cross-linking and interlayer cobonding [20]. It is worth mentioning that there is no DCPD in the first PEDOT layer as it would result in the early polymerization of the PEO precursors thus reducing the final crosslinking with the SPE layer during the final heat treatment. However, during the final heat treatment, the initiator from the second and third layers is assumed to initiate the polymerization of the PEO precursors in the first layer to improve adhesion between all three layers. Finally, the actuator was washed in methanol to remove any unreacted oxidant solution and any weak PEDOT bonds.

The trilayer structures are then micro-patterned into microbeams using laser cutting (refer to supporting information for laser patterning conditions SI1) (Fig. 2). Microbeams were then swollen in ionic liquid (EMImTFSI) until they reached swelling saturation point (around one week) in order to incorporate the ions necessary for the redox process.

\section{Results and discussion}

\subsection{Optimization of electrochemical properties of PEDOT electrodes}

Optimization of LBL synthesized electrodes was carried out in order to obtain highly conductive and electroactive of conducting polymer electrodes (CPE) (PEDOT layers) which are critical parameters for obtaining efficient bending type trilayer microactuators. High electronic conductivity will be necessary to promote fast charge transport along the length of the device and will be involved in the curvature homogeneity of the final beam. Besides electronic conductivity, also volumetric charge density as an indicator of electroactivity, is a critical parameter since the electrode strain is directly proportional to the number of inserted/ expelled ions [29]. In other words, if PEDOT chains are highly conductive but not accessible for insertion/expulsion of ions of the chosen electrolyte, the resulting deformation will be small. For this purpose, the volumetric charge density of each synthesized CPE has been minutely characterized and needs to be as high as possible. Set up are presented in supporting information SI1.

Optimization on PEDOT/PEO electrode properties has been performed first as a function of $\mathrm{MPEG}$ content in the oxidant solution and in the present section all the results for the PEDOT electrodes are given in the swollen state (EMImTFSI), if not stated otherwise.

It was found that while increasing the MPEG content in the oxidant solution, the thickness of the electrodes (Fig. 3a) remained in the same range from $0 \%$ to $20 \%$ mPEG before a drastic increase. A possible reason for the increase in thickness is the prepolymerization of $\mathrm{mPEG}$ in the flask. Indeed, peroxide based initiators, such as DCPD, and $\mathrm{Fe}^{3+}$ ions can react and generate radicals at room temperature [32]. The presence of radicals will lead to a nondesired polymerization of $\mathrm{MPEG}$ in the oxidant solution. While this phenomenon seems rather limited for a low content of MPEG, and a 


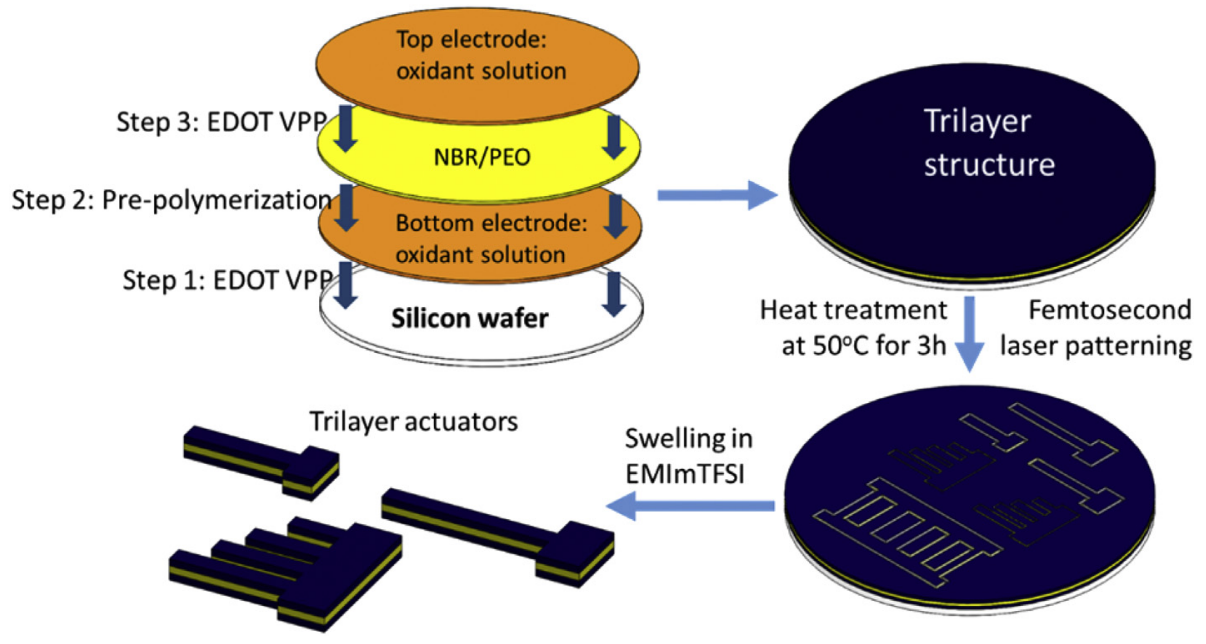

Fig. 2. Microactuator fabrication process.
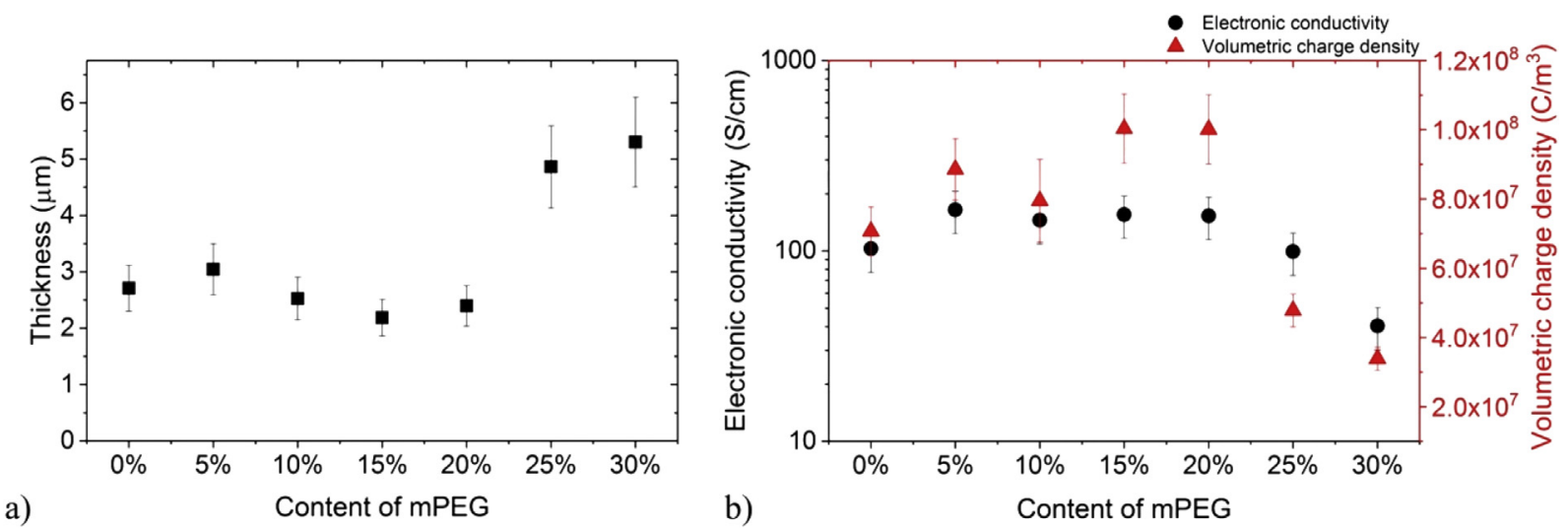

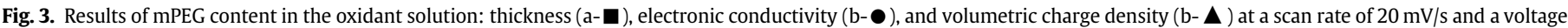
window of $2 \mathrm{~V}$. Spin coating speed/acceleration/duration of oxidant solution: $2500 \mathrm{rpm} / 1000 \mathrm{rpm} \mathrm{s}^{-1} / 30 \mathrm{~s}$; EDOT VPP time: $30 \mathrm{~min}$; EDOT VPP temperature: $40^{\circ} \mathrm{C}$.

low content of DCPD, it becomes obvious for high content of mPEG, since it was found that the bulk polymerization occurs with $50 \mathrm{wt} \%$ of mPEG. As the MPEG and DCPD contents are increased in the oxidant solution, the concentration of monomers and generated radicals are both increasing the polymerization kinetics and promote an increase of viscosity in the flask. The thickness of spincoated oxidant solution layer on the substrate is then higher and leads to the increase in thickness of PEDOT electrode layers.

Adding up to $20 \mathrm{wt} \% \mathrm{mPEG}$ into the oxidant solution leads also to an improvement of the electrical and electrochemical properties of the PEDOT electrodes (Fig. 3b). Adding only $5 \mathrm{wt} \% \mathrm{mPEG}$ to the oxidant solution increases the electronic conductivity from $103 \mathrm{~S} /$ $\mathrm{cm}$ to $164 \mathrm{~S} / \mathrm{cm}$. These results are consistent with the literature indicating that adding glycol based additives [33-35] into the oxidant solution helps to affect positively the synthesis of highly conductive and electroactive PEDOT layers, so in our case, MPEG is behaving as a reactive additive. In contrast, the excess of PEG-based monomers (above $20 \mathrm{wt} \% \mathrm{mPEG}$ ) in the oxidant solution leads to a decrease of both electrical and electrochemical properties, probably due to the increase of non-electrically conducting phase (mPEG) in the electrodes. On the other hand, the reason for the decrease of electrical and electrochemical properties above $20 \mathrm{wt} \%$ mPEG in the electrodes can also be explained by the prepolymerization of mPEG in the flask, which forms thicker and more disorganized electrodes and can result in the loss of charge transport along the electrodes.

Decreasing the rotation speed of the oxidant solution during the spin coating step led to a thicker oxidant solution layer on the substrate and therefore thicker CPE layers (Fig. 4a). Changing the rotation speed did not have a tremendous effect on the electroactivity (Fig. 4b) of the electrode layers, which remain high at all speeds (between $7.9 \times 10^{7} \mathrm{C} / \mathrm{m}^{3}$ and $9.6 \times 10^{7} \mathrm{C} / \mathrm{m}^{3}$ ). A same behavior is also observed with the electronic conductivity i.e. the rotation speed in the range of $1000 \mathrm{rpm}-2000 \mathrm{rpm}$ hardly influences the electronic conductivity values which remain high (around $200 \mathrm{~S} / \mathrm{cm}$ ). Depending on the desired electrode thickness, any rotation speed can be chosen while maintaining the same synthesis conditions ( $10 \% \mathrm{mPEG}$, EDOT VPP for $30 \mathrm{~min}$ at $40^{\circ} \mathrm{C}$ ) to obtain highly conductive PEDOT electrodes with high electroactivity.

The effect of EDOT VPP time on PEDOT electrode properties is described in Fig. 5. While increasing the polymerization time, it can be seen that the thickness of the swollen electrodes (Fig. 5a) is decreasing. Those results were surprising but can be explained when measuring the thickness of dry/non-swollen electrodes. Indeed, the thickness of the dry electrodes is increasing as a function of VPP time as expected. This result points out a decrease of swelling ability of the electrodes while polymerization time is increased, probably related to higher stiffness of the CPE layer. At the same time, the electronic conductivity is decreasing gradually 

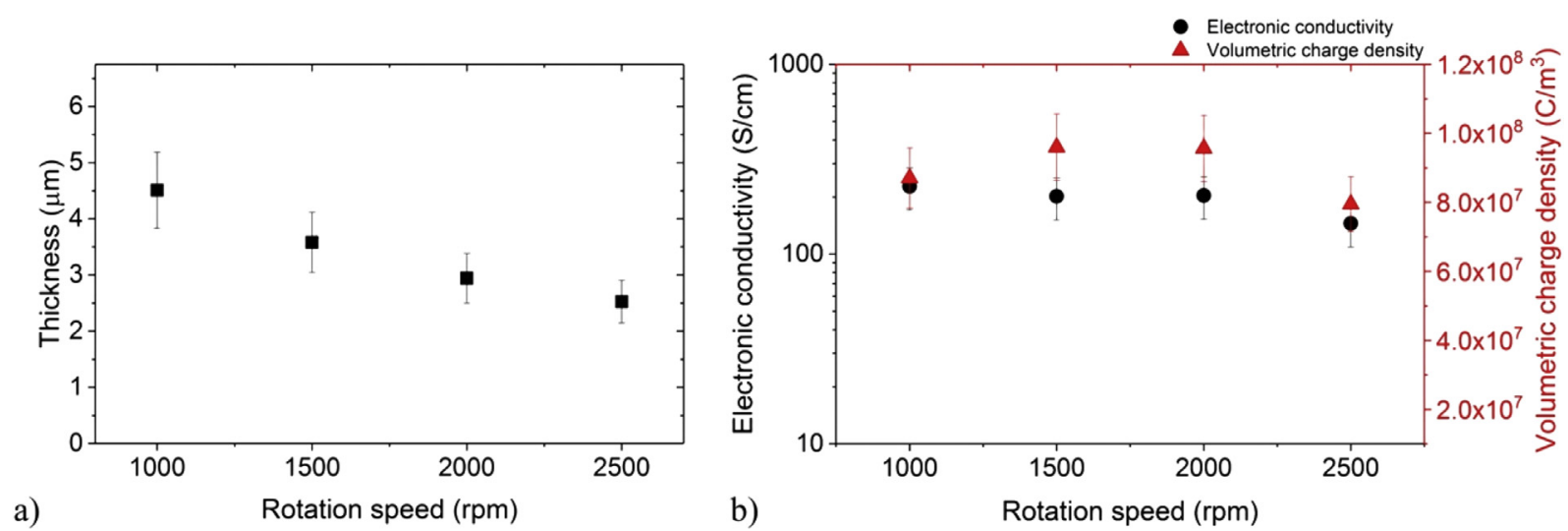

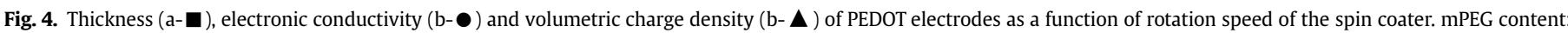
10\%; EDOT VPP time: $30 \mathrm{~min}$; EDOT VPP temperature: $40^{\circ} \mathrm{C}$. Acceleration $1000 \mathrm{rpm} \mathrm{s}^{-1}$, duration $30 \mathrm{~s}$.
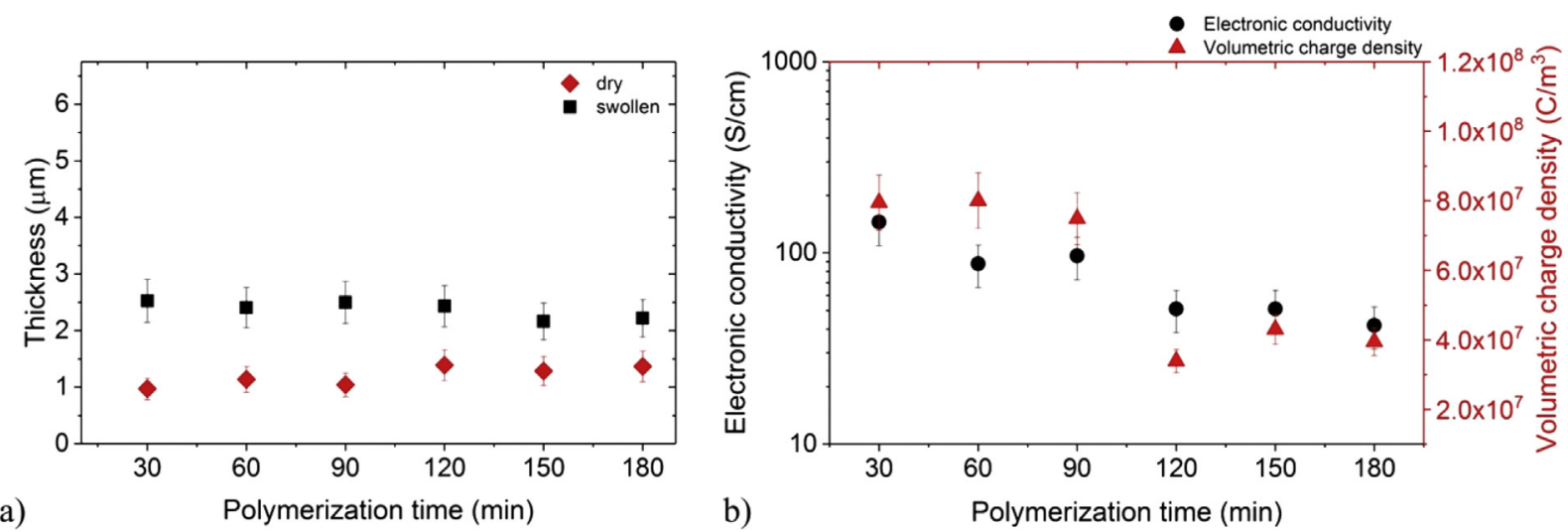

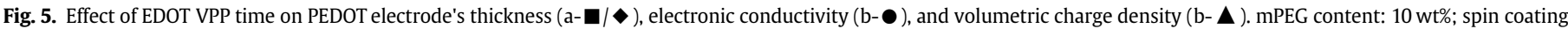
speed/acceleration/duration of oxidant solution: $2500 \mathrm{rpm} / 1000 \mathrm{rpm} \mathrm{s}^{-1} / 30 \mathrm{~s}$; EDOT VPP temperature: $40^{\circ} \mathrm{C}$.

from $145 \mathrm{~S} / \mathrm{cm}(30 \mathrm{~min})$ to less than $50 \mathrm{~S} / \mathrm{cm}$ (180 min) (Fig. $5 \mathrm{~b}$ ). This trend has already been described and explained by the fact that longer polymerization times lead to higher structural disorder or randomly orientated disconnected islands in the polymer. These defects limit charge transport and result in higher resistance on the PEDOT layer [36,37].

Increasing the EDOT VPP temperature also increases the thickness of the PEDOT electrodes because of the higher concentration of EDOT vapor reacting with the surface of the oxidant solution
(Fig. 6a). The higher temperature also allows partial polymerization of PEO during the VPP process which ensures the swelling ability of the electrodes in EMImTFSI, thus avoiding the decrease in thickness as observed while the VPP time was increased. Between $30^{\circ} \mathrm{C}$ and $50^{\circ} \mathrm{C}$ the electronic conductivity (Fig. 6b) lies around 100-150 S/ $\mathrm{cm}$ and a significant decrease to $40 \mathrm{~S} / \mathrm{cm}$ and $4.6 \times 10^{7} \mathrm{C} / \mathrm{m}^{3}$ is observed when the temperature is increasing to $80^{\circ} \mathrm{C}$. The VPP temperature has a great influence on the morphology and the lattice structure of the PEDOT layers. At higher temperature (above
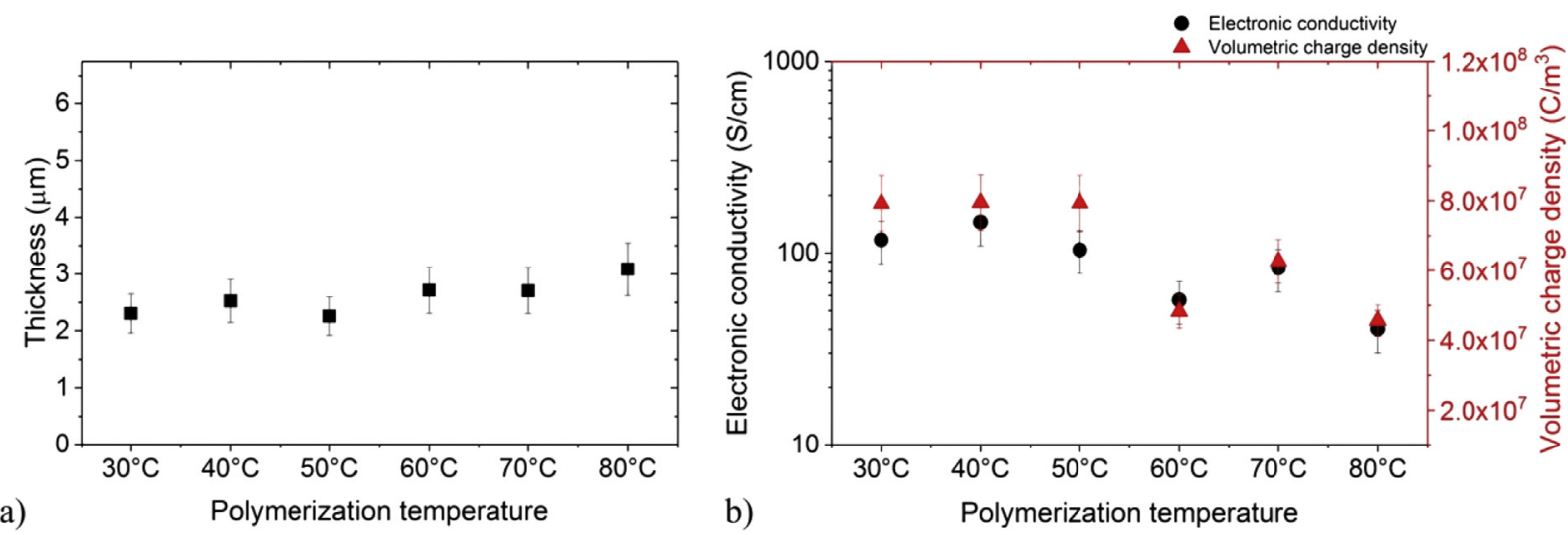

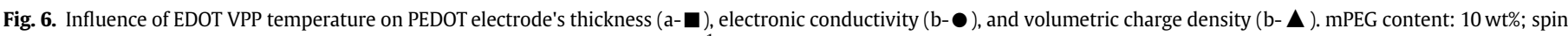
coating speed/acceleration/duration of oxidant solution: $2500 \mathrm{rpm} / 1000 \mathrm{rpm} \mathrm{s}{ }^{-1} / 30 \mathrm{~s}$; EDOT VPP time: $30 \mathrm{~min}$. 
$50^{\circ} \mathrm{C}$ ), the polymerization rate is faster, causing structural disorder in the electrode. It has been shown previously that the optimal VPP temperature for fabricating PEDOT layers is $46 \pm 1^{\circ} \mathrm{C}$. Above this temperature the electronic conductivity of CPE layers decreased because the lattice structure of the PEDOT films had almost no orientation [38].

It can be concluded that to obtain PEDOT electrodes with high electronic conductivity and high electroactivity using VPP, it is necessary to add PEO precursors to the oxidant solution while not increasing their concentration above $20 \%$. The rotation speed can be chosen according to the desired CPE thickness without affecting the electronic conductivity. In addition, the polymerization time and temperature must not exceed $90 \mathrm{~min}$ and $50^{\circ} \mathrm{C}$, respectively, in order to maintain both, high electronic conductivity and electrochemical properties. The optimal parameters resulted in high conductivities (around $200 \mathrm{~S} / \mathrm{cm}$ ) and high electroactivity (between $2.3 \times 10^{7} \mathrm{C} / \mathrm{m}^{3}$ and $1.0 \times 10^{8} \mathrm{C} / \mathrm{m}^{3}$ ). PEDOT electrode thicknesses can be tuned between 0.8 and $5.3 \mu \mathrm{m}$. The optimization of the electrodes in this section helped to determine the right parameters for fabricating highly conductive and electroactive PEDOT electrodes.

\subsection{Trilayer structure}

Consequently, to the previous results, the following parameters for the fabrication of the trilayer actuators using LbL synthesis were chosen in order to obtain a thick, highly conductive and electroactive electrode: mPEG content of $10 \mathrm{wt} \%$, oxidant solution coating speed, acceleration, and duration of $1500 \mathrm{rpm}, 1000 \mathrm{rpm} \mathrm{s}^{-1}$, and $30 \mathrm{~s}$, respectively, and EDOT VPP at $40^{\circ} \mathrm{C}$ for $50 \mathrm{~min}$. PEDOT:NBR/ PEO:PEDOT trilayer morphology was investigated by SEM (Fig. 7a).

The thicknesses of each layer before and after immersion in EMImTFSI are listed in Table 2. The thickness measurements have been performed on a set of five different trilayer samples prepared with the same fabrication process and the consistency of the thickness values in the table below demonstrate the reproducibility of the fabrication process.

It is important to note that after swelling in EMImTFSI, the total thickness of trilayer actuator can be easily verified by SEM (Fig. 7a) but the thickness change of each layer is impossible to determine directly on the trilayer either by SEM or EDX because the ionic liquid covers the cross section of the trilayer. Therefore, a single SPE layer was fabricated using the same parameters in comparison with the SPE layer in trilayer structure. This single layer was then swollen in EMImTFSI during one week. It has been found that SPE layer increases of $64 \%$ its thickness after swelling. From these two results, the thicknesses of two conducting polymer electrode layers

Table 2

Thicknesses of each layer before and after swelling in EMImTFSI.

\begin{tabular}{lll}
\hline Trilayer & $\begin{array}{l}\text { Thickness before } \\
\text { swelling }(\mu \mathrm{m})\end{array}$ & $\begin{array}{l}\text { Thickness after } \\
\text { swelling }(\mu \mathrm{m})\end{array}$ \\
\hline Bottom PEDOT electrode & $2.1 \pm 0.3$ & $3.4 \pm 0.5$ \\
SPE layer & $7.0 \pm 0.3$ & $11.5 \pm 0.5$ \\
Top PEDOT electrode & $2.1 \pm 0.3$ & $3.4 \pm 0.5$ \\
\hline
\end{tabular}

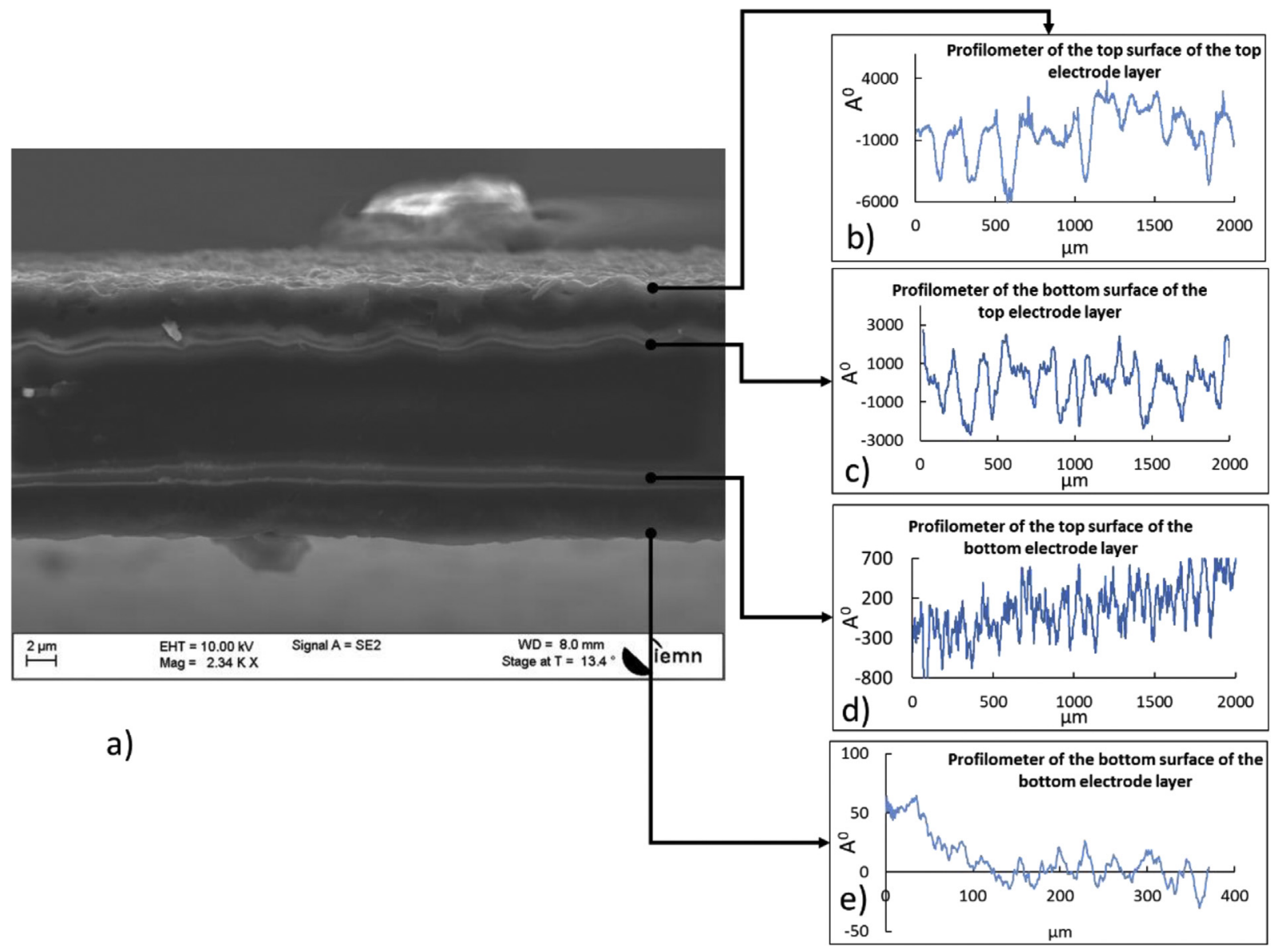

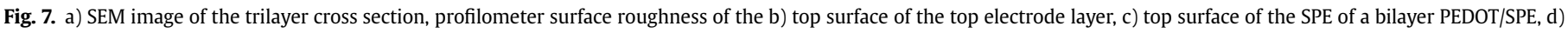
top surface of the bottom electrode layer, e) bottom surface of the bottom electrode layer. 
can be estimated. The error is calculated based on five measurements made at different position along the sample.

Despite the fact of sharing same fabrication parameters, differences between the bottom and top PEDOT layers were observed with the roughness measurements conducted when the layers were still dry. It is worth noticing that the profilometer measurements in Fig. 7c and d were performed on the top surface of the SPE of a bilayer PEDOT/SPE and on the top surface of a single bottom PEDOT layer, respectively. The roughness was measured here while the layers were still on a silicon wafer and the average values obtained are $0.5 \mu \mathrm{m}$ and around $0.1 \mu \mathrm{m}$ respectively. The surface roughness of the top surface of the top electrode Fig. $7 \mathrm{~b}$ is also measured as the actuator is still fixed on the silicon wafer and the average value obtained $(0.7 \mu \mathrm{m})$ is similar to that measured on PEDOT/SPE. The average roughness on the bottom surface of the bottom electrode is measured after lift-off and once it has been flipped on over to a new silicon wafer. The value obtained in this case is very small, around $0.06 \mu \mathrm{m}$ (Fig. 7e) (refer to supporting information SI2). The average roughness of the top PEDOT electrode surface is then ten times higher than for the bottom electrode.

The LbL fabrication method may explain this roughness difference. The SPE layer is spin-coated on the bottom PEDOT layer and the pre-heat treatment (for evaporating the solvent and crosslinking PEO precursors) may result in a slight contraction of this layer, producing a slight and relatively regular folding on its surface. This folding depends on the thickness of the SPE layer and the way in which the heat treatment is performed. The top PEDOT layer only reproduces the shape of the SPE surface. The average roughness of the PEDOT surface in contact with open-air (top PEDOT electrode) (Fig. 7d) is, quite logically, greater than the one in contact with silicon substrate (Fig. 7e). The supposed contraction of the SPE layer during the trilayer fabrication process is visible once the microbeams are lifted off and swollen in EMImTFSI. A slight curvature of the beam often appears which extends systematically the bottom layer of PEDOT previously in contact with the silicon wafer and contracts the top layer of PEDOT. This indicates the presence of a weak stress inside the microbeam which subsequently affects the properties of the beams.

\subsection{Electrochemical characterization}

VCD is a critical parameter to determine the amount of charge uptake by a conducting polymer electrode at a specific scanning voltage speed. This value is used also to calculate the strain-tocharge ratio [29]. The VCD of the trilayer was first characterized under the same measurement conditions as used for the optimization of PEDOT electrodes and actuated using a voltage window of $2 \mathrm{Vpp}$ at scanning rate of $20 \mathrm{mV} / \mathrm{s}$. It was found that the VCD value is $1.0 \times 10^{8} \mathrm{C} / \mathrm{m}^{3}$, which is the same as the highest value obtained in the previous section.

The volumetric capacitance also assesses the effect of scanning rate of applied voltage on the ability to accommodate ions of the conducting polymer film during its actuation. Researchers have recently tried to determine the volumetric capacitance of a pure PEDOT or PEDOT:PSS thin films [39,40]. They found that this capacitance not only depends on the thickness and the density of PEDOT determined by the VPP time and the coating speed but also on the type of dopant, as smaller dopants increase the volumetric capacitance to a certain extent. For our measurement, the working electrode in Fig. SI1a (refer to the supporting information) was connected to both electrodes of the trilayer actuator using platinum clamps and then fully immersed in EMImTFSI. During this experiment, the potential was swept from $V_{1}=-0.6 \mathrm{~V}$ to $V_{2}=0.7 \mathrm{~V} \mathrm{vs}$. Ag/ $\mathrm{AgCl}$ reference electrode at scan rates, $\vartheta$, varying from $0.005 \mathrm{~V} / \mathrm{s}$ to $1 \mathrm{~V} / \mathrm{s}$ (Fig. 8a).

The effective capacitance was derived from the expression [41]:

$\boldsymbol{C}_{\text {PEDOT }}=\frac{\int_{V_{1}}^{V_{2}} \boldsymbol{i}(\boldsymbol{V}) \boldsymbol{d} \boldsymbol{V}}{\vartheta\left(\boldsymbol{V}_{2}-\boldsymbol{V}_{1}\right)}(\mathrm{F})$

Effective volumetric capacitance was calculated from:

$\boldsymbol{C}_{\boldsymbol{V}}=\frac{\boldsymbol{C}_{\boldsymbol{P E D O T}}}{\boldsymbol{L b h}}(\mathrm{F} / \mathrm{m} 3)$

Here, $L, b$, and $h$ are the length, width, and thickness of the total PEDOT electrodes, respectively. The volumetric capacitance allows the extent of charging to be estimated, since its value is proportional to total charge transferred. The amount of charge transferred scales with voltage to a first approximation, providing a number for comparative purposes that, when multiplied by internal resistance, gives an estimate of response time.

As described in Fig. 8b, the accessible volumetric capacitance varies with the scan rate. This value drops gradually from $90 \times 10^{6} \mathrm{~F} / \mathrm{m}^{3}$ at low scanning rate of $0.005 \mathrm{~V} / \mathrm{s}$ to $57 \times 10^{6} \mathrm{~F} / \mathrm{m}^{3}$ which is approximately $63 \%$ of maximum capacity at fairly quick
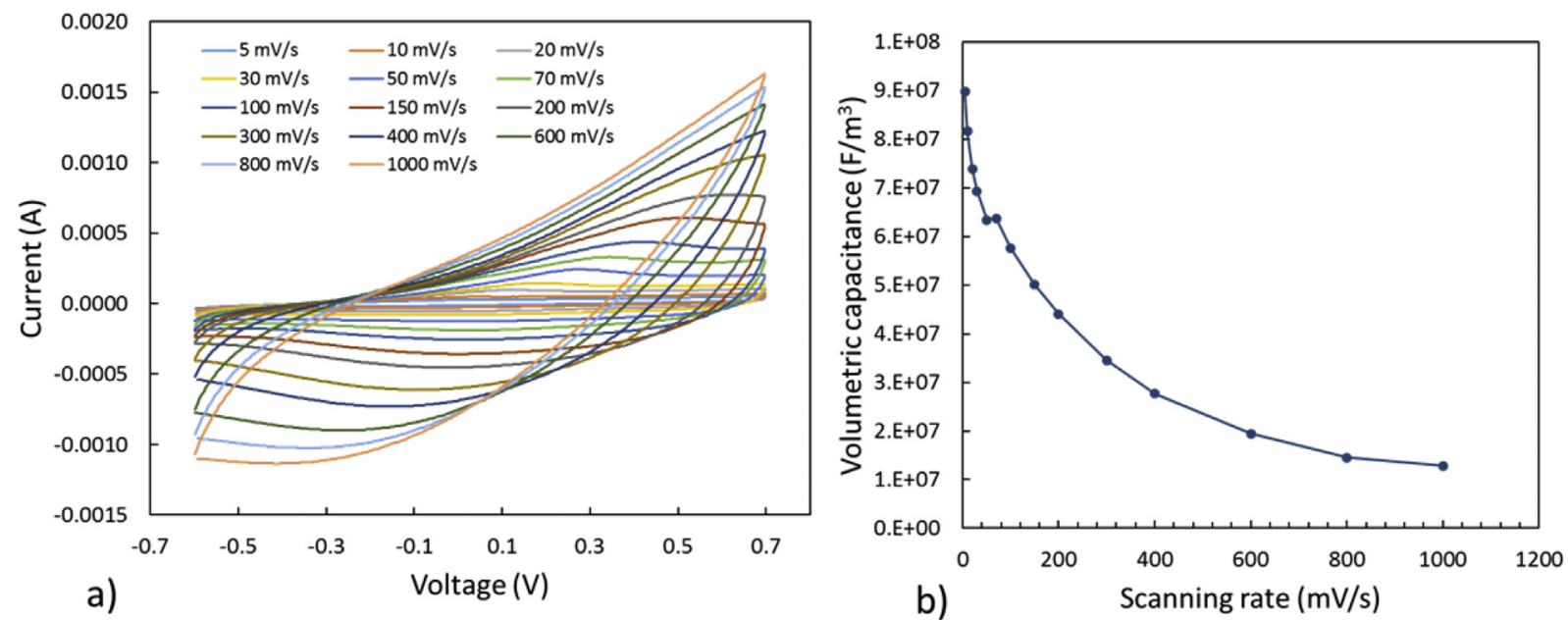

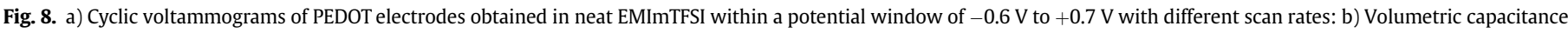
of PEDOT electrodes as function of the scanning rate. 
scanning rate of $0.1 \mathrm{~V} / \mathrm{s}$. This value decreases steadily to $12 \times 10^{6} \mathrm{~F} /$ $\mathrm{m}^{3}$ when the scan rate increases to $1 \mathrm{~V} / \mathrm{s}$. We attribute the ability of the PEDOT samples in this case to charge relatively rapidly in the presence of PEO pores, enabling faster ion transport [42]. Previous work has shown a value of volumetric capacitance of $145 \times 10^{6} \mathrm{~F} /$ $\mathrm{m}^{3}$ for PEDOT-paper, and between $57 \times 10^{6} \mathrm{~F} / \mathrm{m}^{3}$ and $6 \times 10^{6} \mathrm{~F} / \mathrm{m}^{3}$ for PEDOT:PSS $[43,44]$. They have also observed a smooth decrease in this capacitance value with an increasing scan rate. In our work, the volumetric capacitance measurement was conducted at lower scanning rate of $0.5 \mathrm{mV} / \mathrm{s}, 1 \mathrm{mV} / \mathrm{s}$, and $2 \mathrm{mV} / \mathrm{s}$. However, at these extremely low scan rates, the Pt clamp which is used to hold the trilayer as the working electrode and the surface of the PEDOT electrodes expose an apparent capacitance behavior. This capacitance is significant compared to that of PEDOT electrodes in which has a good chance of leading to an incorrect result of estimated PEDOT volumetric capacitance.

In this section, a method to determine the ionic conductivity of the SPE layer is described. The measurements were performed accordingly to the setup described in Fig. SI1c (refer to the supporting information) in which the actuator clamp was made from two gold-coated glass slides and used to clamp the entire length of the actuator. The measurement scheme was derived from an electrical equivalent circuit of a single CPE layer [29] and a bilayer actuator [45] described by an RC transmission line. An electrical equivalent circuit model was then developed for the trilayer actuator as presented in Fig. 9. This model included resistors in the CPE layers: $R_{1 e}, R_{3 e}$, transmission lines through the electrode: $R_{1 i}, R_{3 i}, C_{1 i}$, $C_{3 i}, i=1, \ldots n$, the ionic resistance of the SPE layer $R_{S}$, and the short resistance $R_{\text {short }}$ due to the interpenetration of the PEDOT layers with the SPE layer which could create short circuits in different places along the actuator.

With a high frequency applied voltage $(>1 \mathrm{kHz})$, the capacitor, which is represented by the ionic capacitance of the electrode layers, acts as a short circuit. The red lines represent the current traveling between two gold plates. In this case, the total impedance of the actuator is the same as a pure resistor $R_{t H F}$, which is a function of the short resistance $\left(R_{\text {short }}\right)$ and the ionic resistance of the SPE layer $\left(R_{S}\right)$.

$\frac{1}{R_{t H F}}=\frac{1}{R_{\text {short }}}+\frac{1}{R_{S}}=\frac{1}{139} S$

However, when a DC voltage of $1 \mathrm{~V}$ is applied instead of a high- frequency voltage and maintained long enough to fully charge the capacitors in the electrode layers, these capacitors will then act as open circuits and the current will flow between the two gold plates via $R_{\text {short }}$. The total impedance of the actuator is then equal to $R_{\text {short }}$.

$R_{\text {short }}=226 \Omega$

The total resistance in both cases can be determined according to the relation between the current measured by an ampere meter and the magnitude of the applied voltage. The total ionic resistance $\mathrm{RS}$ is calculated using the following equation:

$R_{S}=\frac{R_{t H F} R_{\text {short }}}{R_{\text {short }}-R_{\text {tHF }}}=363 \Omega$.

And finally, the ionic conductivity of the SPE layer is:

$\sigma_{S}=\frac{h_{S}}{R_{S} L_{S} b_{S}}=0.00028 \mathrm{~S} / \mathrm{cm}$

where $h_{S}, L_{S}$, and $b_{S}$ are the thickness, length, and width of the SPE layer, respectively. This ionic conductivity is three times lower than the value reported in Ref. [46], which concerns a single SPE layer. However, in this trilayer structure, the SPE layer is integrated between the two PEDOT electrodes, which has much higher Young's modulus in comparison to the SPE layer, leading to a reduction of uptake EMImTFSI ions of the SPE layer at the area close to the interface between the two layers, or in other words a limitation of ions accommodation at the interface and thus result in a decrease of the ionic conductivity.

In addition, the electronic conductivity of the bottom PEDOT electrode measured is $18 \mathrm{~S} / \mathrm{cm}$ while that of the top PEDOT electrode is considerably smaller at $2.4 \mathrm{~S} / \mathrm{cm}$ (refer to supporting information for measurement method SI1). Again, these values highlight the asymmetry of the electrical properties of the two CPE layers. These electronic conductivity values are lower than the optimum value of electronic conductivity obtained in the previous section $(\approx 200 \mathrm{~S} / \mathrm{cm})$. These values should be considered qualitative rather than quantitative. In fact, the measured PEDOT film is placed on a SPE layer with the presence of the ionic liquid, and the bottom PEDOT layer has a longer thermal curing time (95 min more) than the single or top PEDOT layer. Consequently, the comparison of the electronic conductivity between the PEDOT single layer and the PEDOT layers in a trilayer actuator cannot be done. However, the

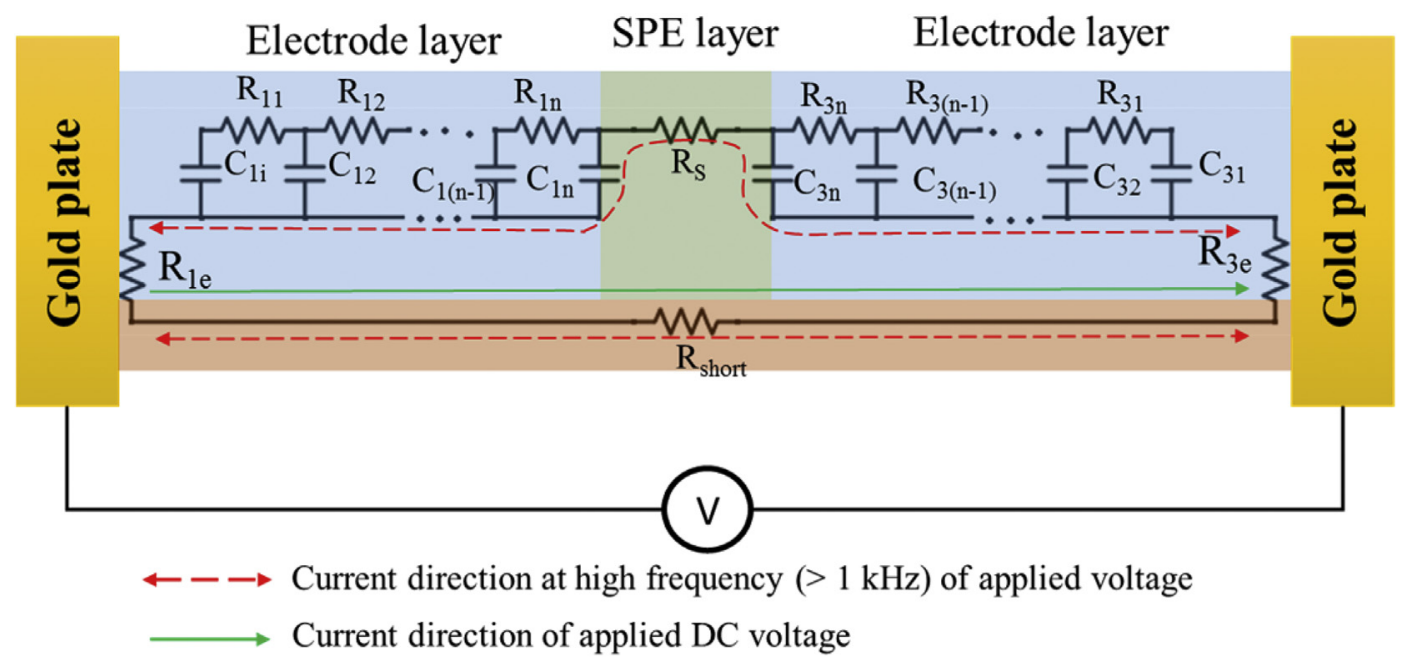

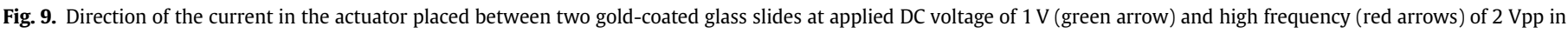
magnitude. (For interpretation of the references to color in this figure legend, the reader is referred to the Web version of this article.) 
asymmetry can be discussed by the means of the fabrication method. Due to the bottom-up forming mechanism, the PEDOT layer is likely denser at the bottom surface than on the top surface. Consequently, the bottom surface of bottom electrode layer is more conductive than the top surface of top electrode. This conductivity difference may be enlarged by the fact that the bottom electrode is smoother and flatter.

\subsection{Mechanical characterization}

A set of five specimens of the SPE material (swollen in EMImTFSI) with the dimension of length $(L) x$ width $(b) x$ thickness $(t)=10 \mathrm{~mm} \times 6 \mathrm{~mm} \times 0.07 \mathrm{~mm}$ has been subjected to a Bose LM1 Test Bench system, according to the setup in Fig. SI1d (refer to the supporting information). A longitudinal displacement has been applied to the SPE sample and the force value has been recorded. The relationship between the force and the displacement gives Young's modulus value of the SPE material as in the following formula. $E_{S P E}=\frac{F}{\Delta L} \frac{L}{b h_{t}}=329 \pm 50 \mathrm{kPa}$ where $F$ is the recorded force, $L$ is the length between two clamping, $\Delta L$ is the beam displacement, $h_{t}$ is the total thickness of the beam, and b is the width of the sample. The Young's modulus of the trilayer structure, which has been swollen in EMImTFSI and measured in the same manner, is $E_{t}=10 \pm 0.5 \mathrm{MPa}$.

In order to determine the displacement of the actuator tip during an electrical stimulation, the experimental setup was prepared as in Fig. SI1c (refer to the supporting information). Since the actuator showed large displacements and an initially curved shape, the most appropriate measurement is through the curvature $\mathrm{K}$, which was obtained by formula [47]:, $K=\frac{1}{r}$ where $r$ is the radius of the curvature. The strain difference $\varepsilon$, between the two PEDOT layers is then derived from: $\varepsilon \%=h_{t}\left(\frac{1}{r_{t}}-\frac{1}{r_{0}}\right)$, where $r_{0}$ and $r_{t}$ is the radius of the actuator at the neutral and the stimulated state, respectively.

Fig. 10a illustrates the bending of the actuator according to the applied voltage, which ranged $3 \mathrm{Vpp}$ of a square wave. The bending experiment also showed non-symmetric displacement. As can be observed, the actuator is not straight at a neutral voltage $(0 \mathrm{~V}$ in red color), suggesting that a pre-stress exists, resulting in an initially curved beam. The actuator tended to bend more when the bottom CPE layer was expanded and the top CPE layer was contracted. In the opposite situation, the actuator bent less. Fig. 10b shows the beam curvature as a function of applied voltage and transferred charge. The curvature increases slightly as the magnitude of the applied voltage reaches $0.8 \mathrm{Vpp}$ at a constant frequency of $0.1 \mathrm{~Hz}$. Between $1 \mathrm{Vpp}$ and $2.4 \mathrm{Vpp}$, the curvature gradually increases which indicates that PEDOT layers are oxidized and reduced and then contribute to actuation as the applied voltage is increased. As the voltage is increased to $3 \mathrm{Vpp}$, the curvature slowly increases and reaches its maximum value at $330 \pm 31 \mathrm{~m}^{-1}$, which is equivalent to a strain difference of $0.50 \pm 0.05 \%$. This result suggests that PEDOT electrodes are approaching fully oxidized and reduced states. As can be seen, the voltage and the charge vs curvature exhibit a nearly identical trend, but do not exactly match. The mismatch can be attributed to the noise at the low range of the current measurement, and the low sampling rate of the multimeter used to record the current, as well as the fast change in current following the step in voltage. Fig. 10c describes the frequency dependence of the beam curvature at a constant voltage of $3 \mathrm{Vpp}$. It shows no change in curvature when the frequency is swept from $0.05 \mathrm{~Hz}$ to $0.1 \mathrm{~Hz}$, and then it drastically decreases to $120 \pm 12 \mathrm{~m}^{-1}$ (equivalent to a strain of $0.18 \pm 0.02 \%$ ) when the frequency increases from $0.1 \mathrm{~Hz}$ to $1 \mathrm{~Hz}$. The reason for that dropping mostly comes from the limitation in the charging time of PEDOT electrodes along its length. A rough estimation can give an idea about the required time to charge these electrodes as mentioned by Madden [29]: $\quad R_{C P} C_{V} V_{C P}=980 \times 50 \times 10^{6} \times 0.006 \times 0.001 \times 0.0000034=1.0 \mathrm{~s}$, where $R_{C P}$ is the resistance value of PEDOT electrode, and $V_{C P}$ is the volume of one PEDOT electrode. The strain value continues to drop moderately up to $10 \mathrm{~Hz}$, and then slowly decreases to a value nonmeasurable at $40 \mathrm{~Hz}$. At these high frequencies of the applied voltage, the other rate limiting factors, electrolyte resistance and ionic resistance of the electrode become apparent, which contributes to the reduced strain.

The force generated at the tip of the actuator of length $x$ width $x$ thickness: $6 \mathrm{~mm} \times 1 \mathrm{~mm} \times 0.0183 \mathrm{~mm}$ at various magnitudes and frequencies of a square wave applied voltage were conducted using the setup described in Fig. SI1c (refer to the supporting information).

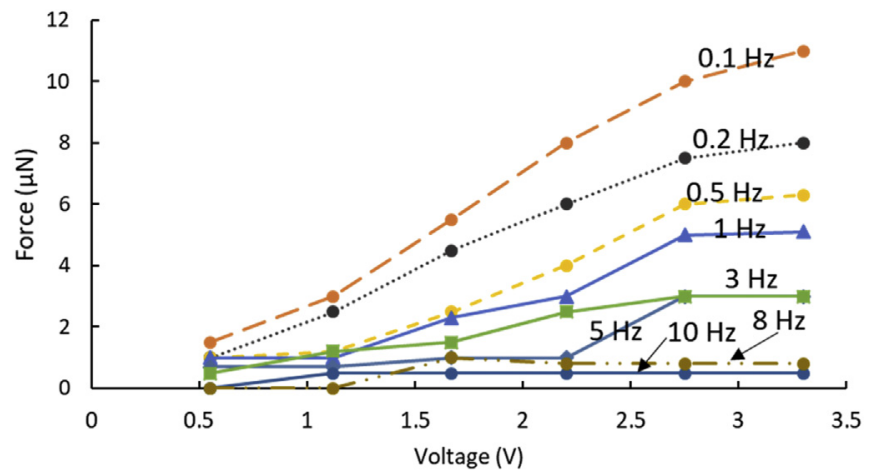

Fig. 11. Force generated as a function of the magnitude and the frequency of the applied voltage from a trilayer actuator of length $\mathrm{x}$ width $\mathrm{x}$ thickness: $6 \mathrm{~mm} \times 1 \mathrm{~mm} \mathrm{x}$ $0.0183 \mathrm{~mm}$
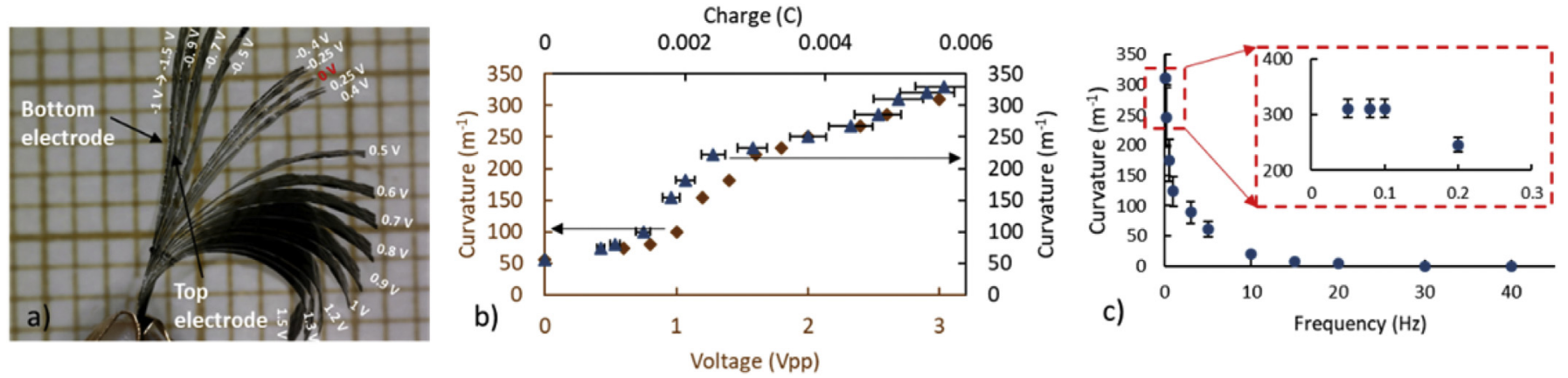

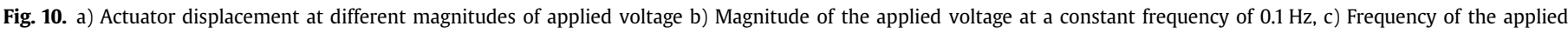
voltage at a constant magnitude of $3 \mathrm{Vpp}$. 
Fig. 11 shows an upward trend in the force generated as the applied voltage is raised. This force decreases when the frequency increases. The force reaches zero or the reading is inaccurate due to background noise when the frequency is $10 \mathrm{~Hz}$. In this experiment, the maximum force obtained at the tip of the trilayer was $11 \mu \mathrm{N}$ at $0.1 \mathrm{~Hz}$ and 3.3 $\mathrm{Vpp}$. It is worth of mentioning that over $2.75 \mathrm{Vpp}$, the generated force almost reaches saturation despite the increase in voltage, indicating that the two PEDOT electrode layers have been fully oxidized and reduced.

\section{Conclusion and future work}

By using the LbL method, we have successfully fabricated functional microactuators with improved performance that are compatible with the microfabrication technology. We have fabricated conducting polymer microactuators, capable of operating in air with a thickness of $11.2 \mu \mathrm{m}$ and $18.3 \mu \mathrm{m}$ in dry and swollen states, respectively. Polymer actuator microbeams were miniaturized by using a laser ablation technique. The optimization and fabrication process were conducted in a clean room to ensure a better repeatability of the manufacturing. To the best of our knowledge, these are the thinnest ionic polymer actuators with such electromechanical characteristics. The electrodes were optimized to obtain highly conductive, electroactive PEDOT layers by taking into account also the volumetric charge density. Trilayer microactuators were fabricated according to the parameters chosen from the optimal ranges of the PEDOT electrode optimization study. The LbL fabrication can induce the advent of a slight stress of the microbeam, which is even more visible as the layer is thin. The electrochemical, electrical, and mechanical properties of the trilayer actuator have been characterized. In particular, the maximum curvature and the maximum force are $330 \mathrm{~m}^{-1}$ at $3 \mathrm{Vpp}$ and $11 \mu \mathrm{N}$ at $0.1 \mathrm{~Hz}$ respectively.

The future work includes further improvement of the measurement of the conductivity of the CPE on the actuators and a more comprehensive characterization and performance of the microactuators. The first generated results will ensure a better understanding of the design and modeling of trilayer actuators, which are a step closer to the control of soft microsystems and microrobotics devices.

\section{Acknowledgments}

This project received funding from the European Union's Horizon 2020 research and innovation program under the Marie Skłodowska-Curie grant agreement No 641822 - MICACT. This work was partly supported by the French Government through the National Research Agency (ANR) under program PIA EQUIPEX LEAF (ANR11-EQPX-0025), RENATECH and MICRO-TIP projects.

\section{Appendix A. Supplementary data}

Supplementary data related to this article can be found at https://doi.org/10.1016/j.electacta.2018.02.003.

\section{References}

[1] S. McGovern, G. Alici, V.T. Truong, G. Spinks, Finding NEMO (novel electromaterial muscle oscillator): a polypyrrole powered robotic fish with real-time wireless speed and directional control, Smart Mater. Struct. 18 (2009).

[2] G.M. Spinks, G.G. Wallace, J. Ding, D. Zhou, B. Xi, J. Gillespie, Ionic liquids and polypyrrole helix tubes: bringing the electronic Braille screen closer to reality, in: Proceedings of SPIE - the International Society for Optical Engineering, 2003, pp. 372-380.

[3] A. Della Santa, A. Mazzoldi, D. De Rossi, Steerable microcatheters actuated by embedded conducting polymer structures, J. Intell. Mater. Syst. Struct. 7 (1996) 292-300.
[4] S. Ramírez-García, D. Diamond, Biomimetic, low power pumps based on soft actuators, Sens. Actuators, A 135 (2007) 229-235.

[5] Y. Wu, D. Zhou, G.M. Spinks, P.C. Innis, W.M. Megill, G.G. Wallace, TITAN: a conducting polymer based microfluidic pump, Smart Mater. Struct. 14 (2005) $1511-1516$.

[6] S.A. Wilson, R.P.J. Jourdain, Q. Zhang, R.A. Dorey, C.R. Bowen, M. Willander, et al., New materials for micro-scale sensors and actuators. An engineering review, Mater. Sci. Eng. R Rep. 56 (2007) 1-129.

[7] D. Pede, E. Smela, T. Johansson, M. Johansson, O. Inganäs, A general-purpose conjugated-polymer device array for imaging, Adv. Mater. 10 (1998) $233-237$.

[8] R. Kiefer, X. Mandviwalla, R. Archer, S.S. Tjahyono, H. Wang, B. MacDonald, et al., The application of polypyrrole trilayer actuators in microfluidics and robotics, in: Proceedings of SPIE - the International Society for Optical Engineering, 2008.

[9] J.D.W. Madden, N.A. Vandesteeg, P.A. Anquetil, P.G.A. Madden, A. Takshi, R.Z. Pytel, et al., Artificial muscle technology: physical principles and naval prospects, IEEE J. Ocean. Eng. 29 (2004) 706-728.

[10] C.A. Cutler, M. Bouguettaya, J.R. Reynolds, PEDOT polyelectrolyte based electrochromic films via electrostatic adsorption, Adv. Mater. 14 (2002) 684-688.

[11] A. Mazzoldi, A.D. Santa, D. De Rossi, Conducting polymer actuators: properties and modeling, in: Y. Osada, D.E. De Rossi (Eds.), Polymer Sensors and Actuators, Springer, Berlin Heidelberg, 2000, pp. 207-244.

[12] E. Smela, Conjugated polymer actuators for biomedical applications, Adv. Mater. 15 (2003) 481-494.

[13] A. Khaldi, C. Plesse, C. Soyer, E. Cattan, F. Vidal, C. Legrand, et al., Conducting interpenetrating polymer network sized to fabricate microactuators, Appl. Phys. Lett. 98 (2011)

[14] A. Khaldi, A. Maziz, C. Plesse, C. Soyer, D. Teyssié, F. Vidal, et al., Patterning innovative conducting interpenetrating polymer network by dry etching, IEEE/ASME International Conference on Advanced Intelligent Mechatronics, AIM2014, pp. 1424-9.

[15] T.F. Otero, J.G. Martinez, J. Arias-Pardilla, Biomimetic electrochemistry from conducting polymers. A review: artificial muscles, smart membranes, smart drug delivery and computer/neuron interfaces, Electrochim. Acta 84 (2012) $112-128$.

[16] T.F. Otero, Biomimetic conducting polymers: synthesis, materials, properties, functions, and devices, Polym. Rev. 53 (2013) 311-351.

[17] D. De Rossi, P. Chiarelli, Biomimetic Macromolecular Actuators, Macro-ion Characterization, American Chemical Society, 1993, pp. 517-530.

[18] Q. Pei, O. Inganäs, Electrochemical applications of the bending beam method; a novel way to study ion transport in electroactive polymers, Solid State Ionics 60 (1993) 161-166.

[19] T.F. Otero, E. Angulo, J. Rodríguez, C. Santamaría, Electrochemomechanical properties from a bilayer: polypyrrole/non-conducting and flexible material - artificial muscle, J. Electroanal. Chem. 341 (1992) 369-375.

[20] D. Mecerreyes, Applications of Ionic Liquids in Polymer Science and Technology, Springer, Heidelberg : New York, 2015.

[21] J. Citerin, A. Kheddar, M. Hafez, F. Vidal, C. Plesse, D. Teyssie, et al., Characterization of a new interpenetrated network conductive polymer (IPN-CP) as a potential actuator that works in air conditions, Intelligent Robots and Systems, in: (IROS 2004) Proceedings 2004 IEEE/RSJ International Conference On2004, vol. 1, 2004, pp. 913-918.

[22] U.L. Zainudeen, M.A. Careem, S. Skaarup, PEDOT and PPy conducting polymer bilayer and trilayer actuators, Sensor. Actuator. B Chem. 134 (2008) 467-470.

[23] C. Plesse, F. Vidal, H. Randriamahazaka, D. Teyssié, C. Chevrot, Synthesis and characterization of conducting interpenetrating polymer networks for new actuators, Polymer 46 (2005) 7771-7778.

[24] A. Maziz, C. Plesse, C. Soyer, E. Cattan, F. Vidal, Top-down approach for the direct synthesis, patterning, and operation of artificial micromuscles on flexible substrates, ACS Appl. Mater. Interfaces 8 (2016) 1559-1564.

[25] J.F. Hulvat, S.I. Stupp, Liquid-crystal templating of conducting polymers, Angew Chem. Int. Ed. Engl. 42 (2003) 778-781.

[26] B. Winther-Jensen, D.W. Breiby, K. West, Base inhibited oxidative polymerization of 3,4-ethylenedioxythiophene with iron(III)tosylate, Synth. Met. 152 (2005) 1-4.

[27] F. Vidal, C. Plesse, G. Palaprat, A. Kheddar, J. Citerin, D. Teyssié, et al., Conducting IPN actuators: from polymer chemistry to actuator with linear actuation, Synth. Met. 156 (2006) 1299-1304.

[28] G. Alici, P. Metz, G.M. Spinks, A mathematical model to describe bending mechanics of polypyrrole (PPy) actuators, in: Proceedings, 2005 IEEE/ASME International Conference on Advanced Intelligent Mechatronics, 2005, pp. $1029-1034$.

[29] J.D.W. Madden, Conducting Polymer Actuators, Massachusetts Institute of Technology, 2000.

[30] P.G.A. Madden, Development and Modeling of Conducting Polymer Actuators and the Fabrication of a Conducting Polymer Based Feedback Loop, Massachusetts Institute of Technology, 2003.

[31] A. Maziz, C. Plesse, C. Soyer, E. Cattan, F. Vidal, Top-down approach for the direct synthesis, patterning, and operation of artificial micromuscles on flexible substrates, ACS Appl. Mater. Interfaces 8 (2016) 1559-1564.

[32] J.F. Perez-Benito, Iron (III)- hydrogen peroxide reaction: kinetic evidence of a hydroxyl-mediated chain mechanism, J. Phys. Chem. 108 (2004) 4853-4858.

[33] M. Mueller, M. Fabretto, D. Evans, P. Hojati-Talemi, C. Gruber, P. Murphy, Vacuum vapour phase polymerization of high conductivity PEDOT: role of 
PEG-PPG-PEG, the origin of water, and choice of oxidant, Polymer 53 (2012) 2146-2151.

[34] K. Zuber, M. Fabretto, C. Hall, P. Murphy, Improved PEDOT conductivity via suppression of crystallite formation in Fe (III) tosylate during vapor phase polymerization, Macromol. Rapid Commun. 29 (2008) 1503-1508.

[35] M. Fabretto, C. Jariego-Moncunill, J.-P. Autere, A. Michelmore, R.D. Short, P. Murphy, High conductivity PEDOT resulting from glycol/oxidant complex and glycol/polymer intercalation during vacuum vapour phase polymerisation, Polymer 52 (2011) 1725-1730.

[36] H. Kim, K. Jeong, C.-J. Yu, H.-S. Nam, H. Soh, J. Lee, The effects of the surface morphology of poly $(3,4$-ethylenedioxythiophene) electrodes on the growth of pentacene, and the electrical performance of the bottom contact pentacene transistor, Solid State Electron. 67 (2012) 70-73.

[37] A. Ugur, F. Katmis, M. Li, L. Wu, Y. Zhu, K.K. Varanasi, et al., Low-Dimensional conduction mechanisms in highly conductive and transparent conjugated polymers, Adv. Mater. 27 (2015) 4604-4610.

[38] D. Wu, J. Zhang, W. Dong, H. Chen, X. Huang, B. Sun, et al., Temperature dependent conductivity of vapor-phase polymerized PEDOT films, Synth. Met. 176 (2013) 86-91.

[39] N. Kurra, R. Wang, H.N. Alshareef, All conducting polymer electrodes for asymmetric solid-state supercapacitors, J. Mater. Chem. 3 (2015) 7368-7374.

[40] C.M. Proctor, J. Rivnay, G.G. Malliaras, Understanding volumetric capacitance in conducting polymers, J. Polym. Sci. B Polym. Phys. 54 (2016) 1433-1436.

[41] M. Ghidiu, M.R. Lukatskaya, M.-O. Zhao, Y. Gogotsi, M.W. Barsoum, Conductive two-dimensional titanium carbide 'clay' with high volumetric capacitance, Nature 516 (2014) 78

[42] J. Xi, X. Qiu, J. Li, X. Tang, W. Zhu, L. Chen, PVDF-PEO blends based microporous polymer electrolyte: effect of PEO on pore configurations and ionic conductivity, J. Power Sources 157 (2006) 501-506.

[43] J.A. Lee, M.K. Shin, S.H. Kim, H.U. Cho, G.M. Spinks, G.G. Wallace, et al., Ultrafast charge and discharge biscrolled yarn supercapacitors for textiles and microdevices, Nat. Commun. 4 (2013) 1970.

[44] Y. Liu, B. Weng, J.M. Razal, Q. Xu, C. Zhao, Y. Hou, et al., High-performance flexible all-solid-state supercapacitor from large free-standing graphenePEDOT/PSS films, Sci. Rep. 5 (2015) 17045.

[45] J.D.M. Tina Shoa, Chi-Wah Eddie Fok, Tissaphern Mirfakhrai, Rate limits in conducting polymers, Adv. Sci. Technol. 61 (2008) 7.

[46] A. Maziz, Microactionneurs à base de polymères conducteurs électroniques vers l'intégration aux microsystèmes par de nouveaux, in: Procédés D'élaboration, Université de Cergy Pontoise, France, 2014.

47] S. Maw, E. Smela, K. Yoshida, P. Sommer-Larsen, R.B. Stein, The effects of varying deposition current density on bending behaviour in PPy(DBS)actuated bending beams, Sensor Actuator Phys. 89 (2001) 175-184. 